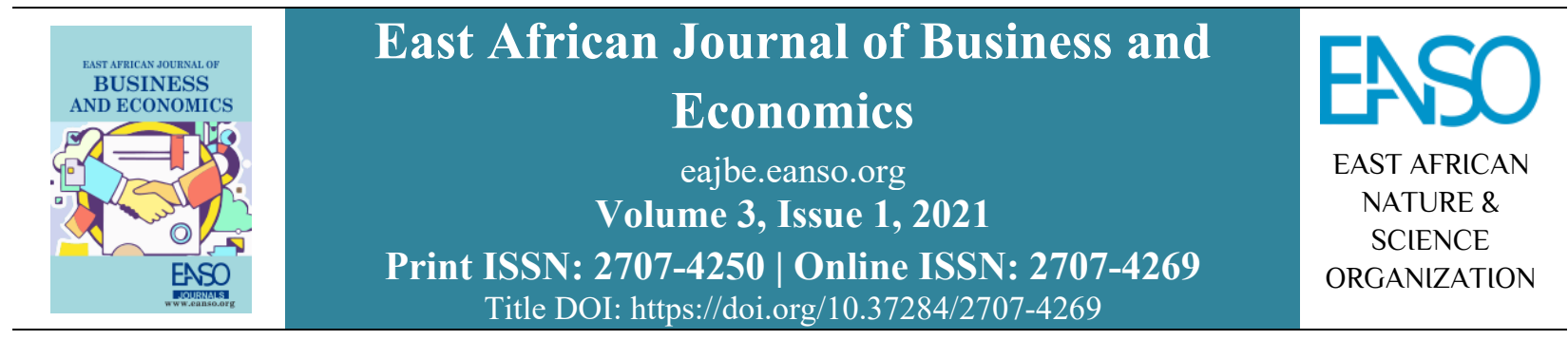

Original Article

\title{
Exploring the Effects of Human Resource Development to Reduce Turnover Intention and Turnover in Public Sector: Comparative Case Study of Korea, Ethiopia, and Rwanda
}

\author{
Pierre Celestin Bimenyimana ${ }^{*}$, Ayele Halefom Abay ${ }^{l}$, \& Healyim Lee \\ ${ }^{1}$ Graduate School of Governance-Sungkyunkwan University, 25-2, Sungkyunkwan-ro, Jongno-gu, Seoul-Republic of Korea. \\ * ORCID: https://orcid.org/0000-0003-4303-8087; Correspondence email: bipiece@gmail.com.
}

Article DOI: https://doi.org/10.37284/eajbe.3.1.284

\section{Date Published: ABSTRACT}

02 March 2021 One of the worldwide important research issues and practical challenges in the public sector is to decrease turnover intention or turnover rate, thereby increasing government overall efficiency and effectiveness. With the world continually changing in this way, it is necessary to invest and educate its members in terms of "human capital" rather than "human resources" so as to survive and flourish. This study explores the effects of human resource development (HRD) to reduce turnover intention and turnover in the public sector. It predicts that HRD consists of enhancing and facilitating the development of capabilities and potentials of individuals, organizations, and communities. The data of the study was collected from 10 respondents working at the Ministerial level in Ethiopia, Korea and Rwanda through inperson, phone and email interviews. Based on literature, we developed a research model, case study research design and qualitative approach was employed in this paper. The results found that there is no direct impact of HRD in reducing turnover intention and turnover however HRD can affect negatively as well as positively employee turnover intentions indirectly. The study suggests that there are should be good HRD Programs for enhancing and facilitating the development of capabilities and potentials of individuals, organizations, and communities.

\section{APA CITATION}

Bimenyimana, P. C., Abay, A. H., \& Lee, H. (2021). Exploring the Effects of Human Resource Development to Reduce Turnover Intention and Turnover in Public Sector: Comparative Case Study of Korea, Ethiopia, and Rwanda. East African Journal of Business and Economics, 3(1), 1-13. https://doi.org/10.37284/eajbe.3.1.284

\section{CHICAGO CITATION}

Bimenyimana, Pierre Celestin, Ayele Halefom Abay, and Healyim Lee. 2021. "Exploring the Effects of Human Resource Development to Reduce Turnover Intention and Turnover in Public Sector: Comparative Case Study of Korea, Ethiopia, and Rwanda”. East African Journal of Business and Economics 3 (1), 1-13. https://doi.org/10.37284/eajbe.3.1.284. 


\section{HARVARD CITATION}

Bimenyimana, P. C., Abay, A. H. and Lee, H. (2021) "Exploring the Effects of Human Resource Development to Reduce Turnover Intention and Turnover in Public Sector: Comparative Case Study of Korea, Ethiopia, and Rwanda", East African Journal of Business and Economics, 3(1), pp. 1-13. doi: 10.37284/eajbe.3.1.284.

\section{IEEE CITATION}

P. C. Bimenyimana, A. H. Abay, and H. Lee, "Exploring the Effects of Human Resource Development to Reduce Turnover Intention and Turnover in Public Sector: Comparative Case Study of Korea, Ethiopia, and Rwanda", EAJBE, vol. 3, no. 1, pp. 1-13, Mar. 2021.

\section{MLA CITATION}

Bimenyimana, Pierre Celestin, Ayele Halefom Abay, and Healyim Lee. "Exploring the Effects of Human Resource Development to Reduce Turnover Intention and Turnover in Public Sector: Comparative Case Study of Korea, Ethiopia, and Rwanda". East African Journal of Business and Economics, Vol. 3, no. 1, Mar. 2021, pp. 1-13, doi:10.37284/eajbe.3.1.284

\section{INTRODUCTION}

One of the worldwide important research issues and practical challenges in the public sector is to decrease officials' turnover intention or turnover rate, thereby increasing government overall efficiency and effectiveness. In the era of the $4^{\text {th }}$ Industrial Revolution, the competitiveness of an organization is determined by its irreplaceable characteristics. With the world continually changing in this way, it is necessary to invest and educate its members in terms of "human capital" rather than "human resources" so as to survive and flourish. Strategic public Human resource development (HRD) program is an essential and integral component in achieving public agencies' mission (Kim et al., 2017) and in creating a learning culture (McCracken \& Wallace, 2000). Previous research (Egan et al., 2004; Joo and park, 2010; Shuck, 2004 etc.) have found crucial implications as studying turnover intention and HRD as an integrated variable. There remains a need for more research to elaborate those variables. From this need, this paper elaborately explores turnover intention by dividing either developmental (e.g., opportunity to make better use of knowledge, skills, and attitudes) or conflictual (e.g., conflict with supervisor or coworker or subordinate, unfair treatment etc.) and also components of HRD- organizational development (OD), career development (CD), and training and development (TD). The purpose of this study is to probe the effect of HRD as well as antecedents of real turnover in the public sector.
Most importantly, this study is significant in that not only it compares and analyses cases of African countries - Ethiopia, Rwanda, and Korea based on the context of each country but also presents practical and theoretical implications from it.

While a number of influential factors might cause turnover and turnover intention, developmental and conflictual turnover intention could be managed through different HRD programs. We hypothesize that HRD and motivation will influence directly and indirectly to "outcome" variables which is turnover intention or turnover. Through this relationship, this paper analysed and compared each case from Korea, Ethiopia, and Rwanda. We begin with the following research questions-these questions applied to each country-:

Research Question 1: Are HRD programs (TD and CD) meaningful to reduce turnover intention (conflictual and developmental)?

Research Question 2: Can HRD programs (TD and CD) motivate officials extrinsically and intrinsically?

Research Questions 3: Does motivation have significant effects on turnover intention?

Research Question 4: What are the major factors contributing to turning turnover intention into real turnover?

This paper consists of five sections. In the introduction, this study explains the problem and 
issues of three countries and explains the explanation of each selected organization. Second, based on the proposed issues, problems are analysed in terms of HRM perspective. Third, supported theories and previous studies are presented and also, a conceptual research framework is provided with information on the data and the measures employed in this paper. The last section proposes the best solution based on possible solutions to increase the effectiveness of the government by reducing the turnover.

\section{Korea: Description of Ministry of Foreign Affairs (MOFA)}

The Ministry of Foreign Affairs carries out foreign policies, economic diplomacy and economic cooperation, takes part in international economic communities, administers treaties and international agreements, protects and supports overseas Korean nationals. It promotes cultural cooperation and analyses international affairs. The structure of MOFA is briefly divided into foreign affairs 1 and foreign affairs 2. Foreign affair 1 is responsible for political affairs, the office of planning and coordination, and protocol affairs and so on. Foreign affair 2 deals with the office of overseas Koreans and consular affairs, global affairs, economic affairs, and security affairs and so on. Besides, there are offices of Korean Peninsula Peace and Security Affairs, Korea National Diplomatic Academy, and other affiliated organizations.

To fulfil the national vision of "A nation of the people, a just Republic of Korea" the Ministry of Foreign Affairs focuses its capacity on the following primary functions of MOFA: 1) peaceful resolution of the North Korean nuclear issue and the establishment of lasting peace, 2) promotion of national interest through public diplomacy and people-centred diplomacy, 3) pursuing confident cooperation diplomacy with neighbouring countries, 4) establishment of a Northeast Asia Community of Responsibility, 5) strengthening trade diplomacy and development cooperation to increase national interest, and 6) protecting the safety of Korean nationals residing abroad and supporting overseas Koreans.

The Human Resources department in MOFA plays an important role in evaluating and managing staff, educating diplomat and administrative officials, recruiting and selecting the right people in a global environment. Also, it is necessary to educate them to get Public Service Motivation (PSM) when working for the nation's mission and being devoted to the public good than to profit. Overseas work, red tape (e.g., making unnecessary documents) and heavy workload and so on can be factors that make it hard to stay in the Ministry of Foreign Affairs. Turnover after training overseas is an issue in MOFA from the HRD and organizational performance perspective.

\section{Ethiopia: Description of Ministry of Federal and Pastoralist Development Affairs (MoFPDA)}

MoFPDA was established in 2001, which was originally "Ministry of Federal Affairs" up to 2015. Because of the development of new issues in the country, the mission, duties and responsibilities of the ministry were becoming broader and broader from time to time. To fulfil its duties and responsibilities the ministry has managed by one minister appointed by Parliament, three deputy ministers appointed by the prime minister, and one head of bureau appointed by the minister. The ministry based on the duties and responsibilities is divided into seven directorate generals under three deputy ministers.

MoFPDA is responsible to ensure equitable development in emerging regions through coordination and integrated effort between federalregional bodies, to ensure sustainable peace and security of the peoples by establishing systems for preventing and resolving conflicts and to uphold and beliefs, and to serve as a focal point of good federal-regional relation. 
Human Resource Management Directorate is organized under the Ministerial office and overseen by both MoFPDA and Ministry of Public Service and HRM. The directorate is responsible for leading all issues related to human resources in the Ministry. The directorate is organized by two teams: HRD team leader and HRM team leader. The directorate is responsible for recruiting and selecting the right person in achieving the goal of the Ministry, planning and implementing training so as to develop the KSA of the staff, rewarding and setting accountability in the Ministry and generally managing the staff. Because of several reasons in Ethiopia moving from Ministry to Ministry and somehow to private organizations is common. The issue of turnover when it comes to MoFPDA is serious which will be discussed in the next part.

\section{Rwanda: Description of Ministry of Local Government (MONALOC)}

The mission of the Ministry is that the Ministry of Local Government ensures "the coordination of good governance and high-quality territorial administration programs that promote economic, social and political development throughout the nation."

According to the Prime Minister's Order No 238/03 of 08/12/2016, the Ministry of Local Government is responsible for: 1) developing, disseminating and coordinating the implementation of policies, strategies and sector programs through the formulation of national policies, strategies and programs of good governance, territorial administration, social affairs and group settlement sites to ensure sustainable community development, 2) developing a legal framework for good governance, territorial administration, settlement and social-economic development and developing institutional and human resources capacities, 3)monitoring and evaluating the implementation of the sector and sub-sector policies, strategies and programs as well as overseeing the functioning of institutions supervised by the Ministry, and
4) promoting effective intergovernmental relationships as well as mobilizing resources for the Ministry activities.

\section{PROBLEM FORMULATION}

In the rapidly changing administrative environment of the 21st century, public servants need a systematic HRD program that not only attracts talented people but also develops their abilities while they continue to work in the public sector so as to make performance. Even though scholars define HRD in a different way, one of the commonly used definitions is that "HRD is a set of systematic and planned activities designed by an organization to provide its members with the necessary skills to meet current and future job demand" (Werner and Desimone, 2006). HRD has been viewed from various perspectives by practitioners and scholars. For example, some researchers stressed critical HRD (Fenwick, 2004; Bierema \& Cseh, 2003) and even treated HRD as the same with HR.

From a practical point of view, there is a risk that employees who have strengthened their competencies through the HRD program will be transferred to other places that provide better conditions. How should an organization prevent competent talent from exiting their organisations? This is a concern for practitioners worldwide, regardless of whether they are public or private. From a theoretical viewpoint, there is criticism that because HRD developed from the United States, it is not suitable for each country that has different situations and contexts and this criticism will make a question that what HRD definition is (McLean \& McLean, 2001).

In the real-world, many Koreans, including high school students, choose public officials as their job because of job security issues, as the new word "gong-ding-jok" in Korea means a compound word of high school students and civil service exam preparation students. In other words, most of them 
prepare public officials for external factors rather than having public values as civil servants. In addition, Ethiopia, Rwanda, and other countries around the world have low external reimbursement systems for civil servants, which mean low salary and low benefit etc. That is, they have the problem of easily moving to a better job if possible. It is important to intrinsically motivate public officials to have loyalty to their organizations and countries in order to solve these problems based on the assumption that the basic level external factors are compensated.

The purpose of this study is to find solutions by focusing on the HRD programs and the motivation of its members, although the turnover intention comes from various causes including environmental, organizational, and personal elements in Korea, Ethiopia and Rwanda cases. This paper employed a qualitative case study methodology considered as a tool to research that facilitates the exploration of a phenomenon within its complex context (Baxter \& Jack, 2008).

\section{The Korean Context}

\section{Turnover Intention}

According to the results of a questionnaire survey by Chosun Biz in 2015, of 14 government ministries and 203 civil servants moved to Sejong City, 85.9\% of respondents said yes to the question, "Do you intend to leave the private sector before retirement?" $75.9 \%$ said they would leave according to conditions, and $10 \%$ said they would like to leave unconditionally. Also, the "Statistical Yearbook of 2015, " issued by the MPM revealed that the number of people who voluntarily retired in 2014 was 24,044 (44 percent) out of 24,652. This is an increase of 3,800 people from 7,086 people in 2013 and nearly double the number of people in 2011 (5,388 people).

Figure 1: The number of early retirement civil servants in Korea

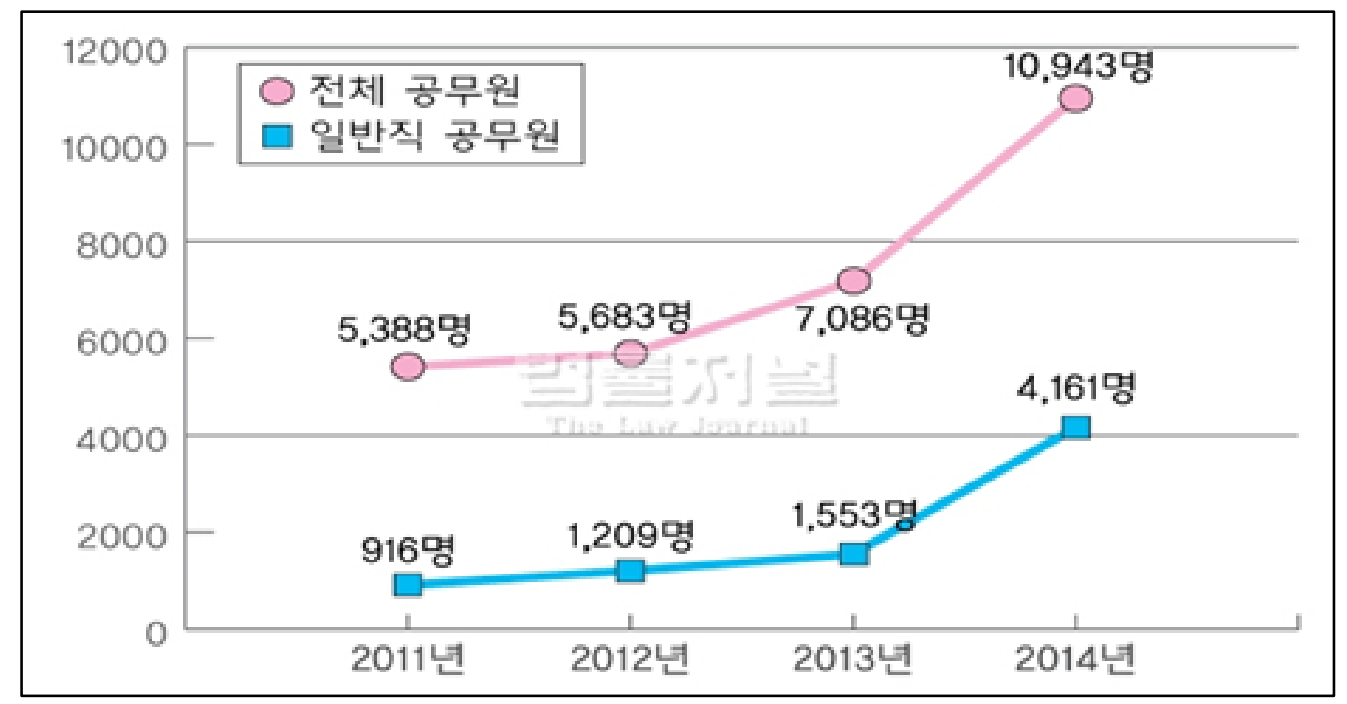

(Pink: total public officials, Blue: public official in general service).

Those turnover or turnover intention can be attributed to the decline in morale due to the Gwanpia (compound words from Bureaucratic and mafia) \& Sewol disaster, the Kim Young-Ran law, and pension reform, an invisible promotion wall and so on. In particular, it was surveyed that the turnover rate of the administrative staff from MOFA is as high as $20 \%$ during the five years (from 2011 to 2015). 


\section{HRD Programs in Korea}

Ministry of personnel management supervises the overall tasks related to human resources development for public officials. The learning system was introduced to improve government competitiveness in order to make the learning organization of the public office society and meet the needs of the knowledge-based and lifelong learning society. In July 2006, provision was made in accordance with the Enforcement Decree of the Public Officials Education and Training Act which made the fact that it is mandatory for officials of grade 4 or below to receive training courses for more than 100 hours a year since 2007 and the results are reflected in the promotion. Based on the MPM website, it provides new recruits with education on public service values, and basic training necessary to perform their tasks. In addition, leadership education is provided to those promoted to deputy director (grade 5), director (grades 3-4), and the SCS.

In the same vein, the National Human resources development Institute (NHI) operates under the ROK Ministry of Personnel Management (MPM) an inter-agency training and performs three basic functions. It has public service values into the overall program and training is the joint responsibility of the officials and his or her supervisor. More importantly, it must meet to be aligned with the organization's goal and objectives by meeting the needs of individuals.

In addition to raising job skills, it has specialized training programs (e.g., public service values promotion program, conflict management skills course, mental healing program, creative minds programs etc.). It also provides international programs for foreign government officials which are customized for single countries such as ODA programs, on-sight joint program, and global leadership program for Uzbekistan government officials and so on.

\section{The Ethiopian Context}

One can easily observe from the above-mentioned vision, mission and duties and responsibilities of the ministry that how much the mission of the organization is hard and complicated. Employees of MoFPDA have to face religious fundamentalism, which is the core problem of the federal system, the region and even the entire world. Because of several reasons conflict frequently occurs between different ethnic groups, for this reason, employees of MOFPDA should have to intervene and solve these conflict issues. These two issues of religious fundamentalism and conflict issues may cost the life of the employees. Employees have also to safeguard the federal system by indoctrinating the federal system throughout the country. Above all to bring about equitable development among regional governments employees of MOFPDA have to travel to remote areas of the country and live in those areas for several times where life is extremely hard.

To perform these complicated tasks, the organization needs to have a strategic HRD system by which to develop the skills and knowledge of the staff. In addition to the training and development program, the organization also needs to provide a career development opportunity to the staff so as to develop their career and motivate. Because of the workload and complexity of the task of the Ministry, the employees have a lot of expectations. Even if the Ministry has an HRD program it is also characterized by a high turnover rate.

According to the annual reports of the ministry from $2011 / 2012$ to $2017 / 2018$, the ministry hired 265 new employees and accepted 35 employees by transfer from regional governments and ministries. This shows as the on average 44 new employees are joining the ministry from the total positions of the ministry. Because of this turnover rate, the experienced, skilled and knowledgeable employees are leaving the Ministry. Apart from the cost of the recruitment process, the ministry is also affected by turnover in performing the goals of the organization. 


\section{The Rwandese Context}

\section{HRD and Turnover intention in Rwanda}

In partnership with different organizations (National and international) like Korean Institute Public Administration (KIPA) under KOICA financing and other experts, the Government of Rwanda has an HRD program for the public officials whereby it is either implemented within the organization or outside the organization. At the national level, it is implemented by the Capacity Development and Employment Services Board in partnership with Rwanda Development Board and Rwanda Management Institute (RMI) for Human Resource Development- Civil Service and Capacity Building (HRD-CSCB). The program itself has the following objective: "enhancing leadership capacities towards performance improvement in the Public sector." All public organizations including the Ministry of Local Government in Rwanda have to plan and implement the annual HRD activities in partnership with the above-mentioned organizations and boards however with such much effort; there is a still turnover intention in the public sector of Rwanda.

A study by the Public Service Commission of Rwanda (2010) found that $68 \%$ of public sector employees had changed institutions more than once between 2008 and 2009. The report by MINECOFIN (2012) also argued that staff turnover was high in some sectors and management experiences serious difficulty in retaining staff, some sectors continue to face challenges in filling positions and experiences high staff turnover. According to Beatrice (2014). the reasons behind turnover intentions in Rwanda are redeployment, different salaries in different public organizations/institutions, employees working far from their families, and looking for a good working environment. Also, the turnover intentions among employees can affect negatively the employee as well as the organizational performance due to the lack of focus on the current position.

\section{LITERATURE REVIEW}

\section{HRD (Human Resource Development)}

Despite the importance of HRD, there is no agreed definition of HRD because it is considered differently depending on the country or context. Even some researchers stressed critical HRD (Fenwick, 2004; Bierema \& Cseh, 2003). McLean and McLean (2001) did research to find definitions and beneficiaries of HRD to define HRD in a global context. As seeing the result from their study, researchers summarized HRD definitions and beneficiaries by country and proved that individual (TD and CD) or organization (OD) were considered as main beneficiaries. However, some countries have a different view to see HRD scope; Thailand (Na Chiangmai, 1998) included the community with the definition 'HRD is an interactive process of enhancing and facilitating the development of capabilities and potentials of individuals, organizations, and communities through organization development and community development to attain effectively, efficiently and harmoniously personal and organizational goals, as well as communal goals". Based on global context and definitions, the paper defined HRD as:

Human resource development is any process or activity that, either initially or over the long term, has the potential to develop adults' workbased knowledge, expertise, productivity and satisfaction, whether for personal or group/team gain, or for the benefit of an organization, community, nation or, ultimately, the whole of humanity.

In McLagan's landmark study (1989) of HRD, HRD is defined as "the integrated use of training and development (TD), career development (CD), and organizational development (OD) to improve individual and organizational effectiveness. However, a few studies consider OD differently from HRD from the perspective that TD and CD are on the focus of individual, but OD is organizational 
(Ruona., \& Gibson, 2004, Grieves, Redman, 1999). In a similar vein, this paper focuses on $C D$ and $T D$ as an HRD variable to explain the research model.

\section{Turnover Intention and Turnover}

There are two types of turnover intention, developmental TI and conflictual TI. Kim and Park (2014) divided the TI into two types: '1) developmental TI: turnover intention caused by human resource development (HRD) opportunities or by the desire to make more of a difference and 2) conflictual TI: turnover intentions caused by organizational and interpersonal conflicts within an organization'. In this study, each TI was affected directly and indirectly by job satisfaction, interpersonal trust, and motivation (intrinsic and extrinsic). Until now, turnover intention has been studied from various angles by various factors. The most common factor which has a negative relationship with turnover is job satisfaction (Kim and Park, 2014; Tett and Meyer, 1993; Poon, 2004 etc.). Cole and Bruch (2006) analysed the organizational effects on turnover intention with the variables -organizational identity strength, organizational identification, and organizational commitment. Poon (2004) investigated the relationship between performance appraisal politics and turnover intention. Also, there was interesting research which showed the effect of ethical climate on turnover intention (Mulki et al., 2008), reflected work context with cooperate ethical values and group creativity (Valentine et al., 2011) and had a model of the social network, P-O value fit, and turnover intention (Moynihan and Pandey, 2007) In this way, it is also necessary to find the influencing factors that lead turnover intention to turnover.

\section{Intrinsic and Extrinsic Motivation}

There hasn't a commonly accepted meaning to define motivation. Atkinson (1964) described that "the study of motivation has to do with the analysis of the various factors which incite and direct an individual's action" (p. 1). Lawlar et al. (1995) define motivation as "Motivation is influenced by forward-looking perceptions concerning the relationship between performance and reward, while satisfaction refers to people's feeling about the rewards they have received". Scholars presented various experiments and theories to find out what motivates people. Experimental studies of Hawthorne in the 1930s are typical. After Maslow published "A Theory of Human Motivation" in 1943, which presented human motives in five sequential ways. Accordingly, various theories appeared to explain what motivates people (e.g. McGregor (1957) - XY Theory, Herzberg (1968) two-factor theory, Vroom (1964) - Expectancy theory, Adam (1951) - Equity theory, Ryan and Deci (2000) - SDT theory, PSM etc.). However, in this study, we identify the influence by dividing it into 1) extrinsic motivation -monetary rewards, promotions, high salary etc. - and 2) intrinsic motivation-noncash recognition from colleagues, PSM, self-esteem and self-actualization etc.-.

\section{Alignment Theory}

Alignment theory made an assumption which officers' perceived interests strive toward goals that can align with the organization. The alignment of individual and organizational goals reduces friction between individuals and the company which will lead to job satisfaction (Semler, 1997). Workman (2003) asserted that when an organization is well aligned with, measurement and reward system match to organizational processes and objectives. Based on this logic, this study hypothesizes that the HRD program provided by the organization will have a positive synergy effect in connection with organizational goals and personal careers.

\section{RESEARCH MODEL}

Based on the Literature review and problems, we developed our research model, seen in Figure 2. This paper used a standard case study methodology that included document analysis and interviews. This study conducted an interview to find empirical 
evidence as to what extent HRD programs have effects on motivation and turnover intention in the public sector.

Figure 2: Research Model

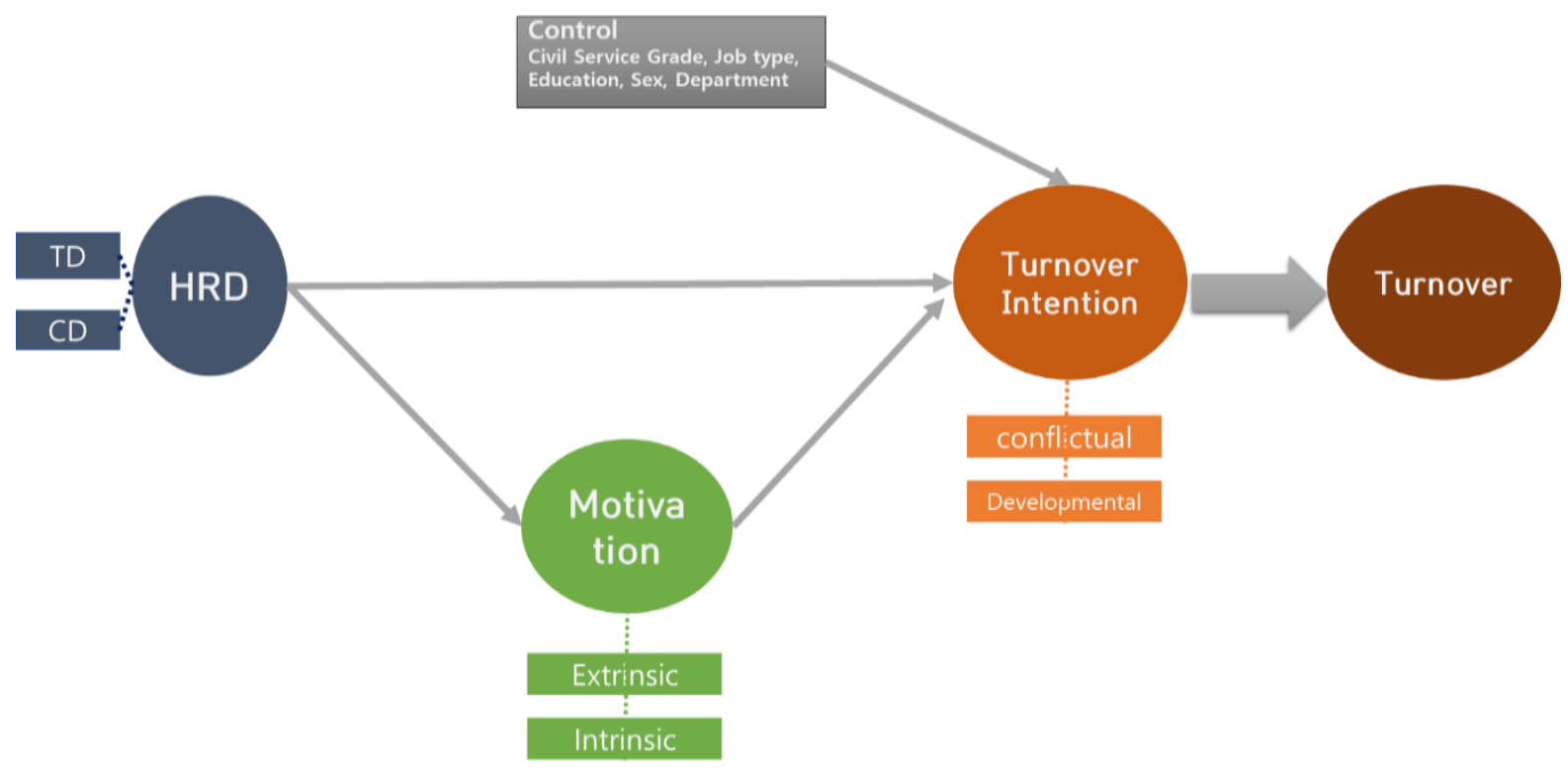

\section{Data and Methodology}

Based on the Literature review and problems, we developed our research model, seen in figure 2. Case study research design and qualitative approach were employed in this paper. A sample of $10-2$ Koreans, 4 Ethiopian, and 4 Rwandan- response was used and content analysis was analysed to research qualitative data. A sample of 10 informants was selected through purposeful sampling. Out of 10 interviewees, there were 5 HR experts who were selected due to their many years of experience in the HR field. Some interviews were conducted over the phone with semi-structured questions, but most were done via email with structured questions. We asked 12 questions in each interview to explore our theoretical model.

How do you evaluate the level of turnover intention in your organization?
Why do you think employees tend to leave the organization?

Is the turnover intention related to conflictual (conflict with supervisor or co-worker or subordinate, unfair treatment etc.) or developmental (opportunity to make better use of KSA (Knowledge, skills, and attitudes), increased opportunities for advancement) turnover intention?

How do you evaluate the current training and development program of your institution? Do you think your organization has good programs for training individual officials' KSA and are you satisfied with the program the ministry has?

How do you evaluate the career development program of the ministry? Do you think your organization has a good program to make each individual feel motivated and progress and are you satisfied with the program the ministry has? 
How do you evaluate the relationship between the HRD program of the ministry (both training development and career development) and the motivation of employees?

What kind of HRD system do you propose to motivate the employees in the ministry?

How do you evaluate the role of the HRD program and its implementation towards reducing the level of turnover intention (both developmental and conflictual) in the ministry? Do you think HRD will help in reducing turnover?

Do you think the employees in your ministry are highly concerned in serving the society and feel as a citizen public service is their duty?

From extrinsic motivation (e.g., reward and salary) and intrinsic motivation (e.g., autonomy and belongingness to organization, public service motivation), which one motivates the employees in your ministry and is crucial in reducing turnover intention?

In your ministry what are the major factors contributing to turning turnover intention into real turnover?

Would you briefly explain if you have any additional opinions related to HRD, motivation and turnover intention in your ministry?

Based on the questions above, the question was translated into Amharic or Kinyarwanda or Korean and then translated into English again for interpretation of the results.

We also conducted an in-depth interview with an HRD expert about the current situation and trend of the Korea HRD filed in the public and private sector. He works at Korea Productivity Center (KPC) which is at the boundary between private and public organization for over 3 years. The length of the interview ranged from one-to-one half-hour with open-ended and unstructured, allowing the respondent to express his opinion.
All respondents were asked about demographic characteristics such as sex, educational level, position, and major. Also, no monetary reward was offered to the respondents. Before conducting an interview and in-depth interview, the interviewers informed the interviewees about the study purpose and application plan to the research so that they know how the answers will be used. The study was testing the case of three countries in terms of HRD and turnover intentions and it significantly found that there is good practice that each of the three countries can learn from others.

\section{CONCLUSION: SOLUTION TO THE PROBLEM/ISSUE}

To summarize the interview results, it was found that HRD is not a direct or causal variable affecting turnover in all countries. Nevertheless, respondents were aware of the impact and ramifications of HRD on the motivation and turnover intentions of its members. It is also important to manage factors that make real turnover as much as managing antecedents of turnover intention.

This study has a theoretical significance because it confirms that the hygiene factor from Herzberg's (1959) Two Factor Theory. This research model captures the hygiene factors as an influencing factor between turnover and turnover intention because it is mostly coming from working conditions, salary, wage relationships with peers and subordinates etc. As for motivator factors such as achievement, recognition, and responsibility can make effects to motivate officials with HRD program. This study also contributed the theoretical contribution in support of the results of Workman's alignment theory (2003) since it has proven that matching the goals of individuals and organizations within the organization can motivate employees and lower turnover intentions. Finally, this study contributes to extend the scope of HRD and turnover intentions study by comparing three countries in Korea, Ethiopia, and Rwanda and also present more research questions for future study. 
The purpose of this study is to apply insights from Korea to Rwanda and Ethiopia case. Of course, it should be applied in consideration of the differences in organizational structure and system and so on. Firstly, as in Korea, the HRD program should legally enact laws with specific hours in Rwanda and Ethiopia. However, it should be guaranteed that autonomy to choose the program they will take. To do this, the government should develop various programs in cooperation with government agencies as well as private educational institutions. In addition, a strategic and institutional program should be providing with need assessment to increase motivation intrinsically and extrinsically. In addition, the scope of HRD should be extended. For example, customized programs should be implemented based on different job characteristics. It doesn't need to be a lecture or class format, but it could be programmed with family members to boost their loyalty in front of children. Similarly, organizations need to develop a creative program out of the typical program. According to the survey with Korean civil servants, they want to have more participatory programs such as flip learning, design thinking and ask \& answer techniques. So those interactive programs should also be introduced in Ethiopia and Rwanda, including Korea, to improve the efficiency and effectiveness of HRD.

This study provides practical implications for each country's situation and survives.

\section{MOFA and Korea Public Sector}

The impact of HRD is invisible and consistent with the long-term prediction. In Korea, employees did not recognize direct causal relationships, but their importance was recognized. In other words, CD and TD can influence indirectly or directly the turnover intention, and for this, it is a must in the organization. In particular, employees were more intrinsically motivated due to the work and characteristics of the Ministry of Foreign Affairs, and the influence of intrinsic motivation was much greater than extrinsic motivation. However, there was a gap between expectation and reality among factors that induce turnover. Before working at the Ministry of Foreign Affairs, individuals could expect that they would do something for the country but in reality, they did unnecessary paper works or repetitive work, thereby their intrinsic motivation was weakened. We also confirmed that there is a lot of education opportunities such as overseas work and overseas training for the officials in the Ministry of Foreign Affairs and that there is a lot of developmental turnover intention.

From these results, the following practical implications were derived. First, new education of TD should be introduced to reduce the difference between reality and expectation. For example, when workers know what an individual's job is in the overall process, they can become more responsible for their duties. They also reduce the idea that your job is trivial or repetitive. Second, intrinsic motivation is also crucial to reduce developmental turnover. Employees already with KSA receive a lot of offers from the outside (private business), and their ability to prevent their turnover is to make them proud to work for the country in the Ministry of Foreign Affairs and to boost organizational commitment. For example, the award or recognition received from an organization or colleague will enhance their intrinsic motivation. In addition, in order to manage them, it is necessary to continuously check the psychological state of workers through periodical consultation and evaluation etc. from an organizational level.

\section{MoFPDA-Ethiopia}

Based on the result from the interview and my own observation there is no direct relation between HRD and turnover intention in MoFPDA. However, HRD influence turnover positively and negatively in a way that by motivating the staff it contributes to retaining the employee and especially after acquiring long-term training the skill, knowledge, qualification and ability of the employee increase cause developmental turnover intention. So even if 
the basic cause for turnover in the Ministry is a low payment, improving the HRD program and implementing strategically will contribute to reducing turnover intention in the Ministry. The following are the major practical suggestion.

\section{Payment}

Ethiopia has different types of payment systems or salary scale within government Ministries. This intern leads to a difference in payment and nonsalary benefits from Ministry to Ministry. In addition to this, most employees believe that the workload and complexity of the organization's mission do not match with the salary scale of the organization. Because of this, the middle-level leaders and senior professional staff are leaving the organization. In 2017/2018 two General Directors of Conflict Prevention and Resolution and Equitable Development leave the organization. So, introducing a national payment system that leads to equal pay to equal job, educational background and experience and harmonizing the complexity of the organizational mission with fair payment and nonsalary benefits of the employee are important measures in motivating the staff and decreasing turnover.

\section{HRD}

Even if the Ministry has relatively better HRD and HRM programs, there are still areas of improvement. The need to align career development or vertical promotion and training opportunities with performance or result-oriented because most employees could get horizontal promotion and training opportunity based on year of experience which might demotivate the best performers of the organization. The training program is not planned and strategically administered; there is no need for assessment and critical evaluation of the training. It has been led traditionally and more focus is given to human resource management than HRD. Especially after long term training, the organization needs to align the major with the right job because after studying when employees come back to their organization, they will be placed in a position that doesn't fit their profession. In addition, since there is no chance of promotion for senior staff after reaching the senior level the Ministry needs to implement horizontal promotion so as to retain them.

\section{Motivation}

Based on the result of the interview and the researcher's personal observation motivation is contributing positively to retaining the staff or reducing turnover. But there are also areas of improvement in this case too and these are the need to reward the best performers on a continuous base and coaching and supporting the poor performers and introducing non-salary benefits like transportation and housing.

In addition to all these, there are also areas of improvement regarding good governance and the democratic culture of the organization which has its own role in increasing turnover in the Ministry. Among these he needs to be responsive to good governance issues from the employees and improving the employee-management relation are the basic ones.

\section{Rwanda- MINALOC}

The study focused on identifying causes of turnover intention in the Ministry and sees some lessons we can draw from the best practices but also providing recommendations about what we can learn from the other two countries. From the literature review, on HRD, TI \& Motivation in MINALOC of Rwanda, the following conclusions can be formulated and recommended:

There is a need for strong partnerships in the implementation of the HRD program by different public organizations so as to help each other; vertical employee promotion is a positive factor to reduce TI, in this context the government of Rwanda can think of internal recruitment and 
promotion; there should be an assessment on the effects of serving three years on the same position before being eligible to leave so as to allow the employee to work for the organization of his choice any time because TI is not always bad for the employee as well as for the organization; making civil servants accountable to the citizens can be a factor to increase intrinsic motivation, and finally, there should be also harmonization of salaries and other job-related benefits in all public organizations with similar characteristics.

In Short, a good HRD program is necessary and has a positive impact on employee motivation and performance. The program can affect negatively as well as positively employee turnover intentions whereby for example an employee after attending training, is qualifying and attractive to new employers for new positions (increase in developmental $\mathrm{TI}$ ), in another view an employee will feel comfortable with his previous position because of new knowledge and skills. Finally, once an employee is motivated, the turnover intention goes down.

Despite these theoretical and practical implications, this study has the following limitations. First, this study limits the use of a single methodology. A mixed-method approach is suggested with both quantitative and qualitative data in future studies to generalize the result. Finally, the variables that influence turnover and turnover intention like mentioned literature review are diverse so if we reflect on this further study, we can get more validity.

\section{REFERENCES}

Atkinson, J. W. (1964). An introduction to motivation. New York: Van Nostrand Reinhold.

Baxter, P., \& Jack, S. (2008). Qualitative case study methodology: Study design and implementation for novice researchers. The qualitative report, 13(4), 544-559.
Bierema, L. L., \& Cseh, M. (2003). Evaluating AHRD research using a feminist research framework. Human Resource Development Quarterly, 14(1), 5-26.

Cole, M. S., \& Bruch, H. (2006). Organizational identity strength, identification, and commitment and their relationships to turnover intention: Does organizational hierarchy matter? Journal of Organizational Behavior, 27(5), 585-605.

Egan, T. M., Yang, B., \& Bartlett, K. R. (2004). The effects of organizational learning culture and job satisfaction on motivation to transfer learning and turnover intention. Human resource development quarterly, 15(3), 279-301.

Fenwick, T. J. (2004). Toward a critical HRD in theory and practice. Adult Education Quarterly, 54(3), 193-209.

For example, G4-G9 officials should have 100 hours or more individual learning hours to promote. $40 \%$ of them should be directly related to job functions and responsibility through public or private HRD centre, government agency, and Internet. On the other hand, remaining $60 \%$ is about self-development which might not be related to job functions.

Joo, B. K. B., \& Park, S. (2010). Career satisfaction, organizational commitment, and turnover intention. Leadership \& Organization Development Journal, 31(6), 482-500.

Kim, M. Y., Yu, H. J., \& Park, S. M. (2017). Examining and testing the roles of human resource development (HRD) in the public sector: evidence from US federal agencies. International Review of Public Administration, 22(1), 60-86.

Kim, S., \& Park, S. M. (2014). Determinants of Job Satisfaction and Turnover Intentions of Public Employees: Evidence from U.S. Federal 
East African Journal of Business and Economics, Volume 3 Issue 1, 2021

Article DOI: https://doi.org/10.37284/eajbe.3.1.284

Agencies. International Review of Public Administration, 19(1), 63-90.

McCracken, M., \& Wallace, M. (2000). Towards a redefinition of strategic HRD. Journal of European industrial training, 24(5), 281-290.

McLagan, P. (1989). Models for HRD practice. Training and Development, 43(9), 49-59.

McLean, G. N., \& McLean, L. (2001). If we cannot define HRD in one country, how can we define it in an international context? Human Resource Development International, 4(3), 313-326.

MINECOFIN. (2012). EDPRS: Lesson Learned: 2008-2011. Kigali: Government of Rwanda.

Moynihan, D. P., \& Pandey, S. K. (2007). The ties that bind: Social networks, person-organization value fit, and turnover intention. Journal of Public Administration Research and Theory, 18(2), 205-227.

Mulki, J. P., Jaramillo, J. F., \& Locander, W. B. (2008). Effect of ethical climate on turnover intention: Linking attitudinal-and stress theory. Journal of Business Ethics, 78(4), 559574.

Na Chiangmai, C. (1998). Current outlook and trends of HRD in Thailand, handout distributed at international HRD course, University of Minnesota, St. Paul, MN, 1 October.

Poon, J. M. (2004). Effects of performance appraisal politics on job satisfaction and turnover intention. Personnel review, 33(3), 322-334.

Public Service Commission. (2010). Baseline Survey on Causes of Work Conflicts, Labor Mobility, Skills and Competencies. Kigali: Government of Rwanda.

Ruona, W. E., \& Gibson, S. K. (2004). The making of twenty-first-century HR: An analysis of the convergence of HRM, HRD, and OD. Human Resource Management, 43(1), 49-66.

Shuck, B., Twyford, D., Reio, T. G., \& Shuck, A. (2014). Human resource development practices and employee engagement: Examining the connection with employee turnover intentions.Human Resource Development Quarterly, 25(2), 239-270.

Uwamariya, B. (2014). Social Economic Factors Contributing To Employee Turnover in Health Care Institutions of Rwanda: Case Study of Nyanza District. Doctoral dissertation. UNILAK.

Valentine, S., Godkin, L., Fleischman, G. M., \& Kidwell, R. (2011). Corporate ethical values, group creativity, job satisfaction and turnover intention: The impact of work context on work response. Journal of Business Ethics, 98(3), 353-372.

Werner, J. M., \& DeSimone, R. L. (2006). Human resource development $\left(4^{\text {th }} \mathrm{Ed}\right)$. Mason, $\mathrm{OH}$ : Thomson-Southwestern.

Workman, M. (2003). Results from organizational development interventions in a technology call center. Human Resource Development Quarterly, 14(2), 215-230. 